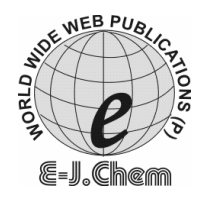

\title{
Cellulose Sulfonic Acid: An Efficient Heterogeneous Catalyst for the Synthesis of 1, 8-Dioxo-octahydroxanthenes
}

\author{
HOSSEIN A. OSKOOIE, LEILI TAHERSHAMSI, \\ MAJID M.HERAVI* and BITA BAGHERNEJAD \\ Department of Chemistry, School of Science, \\ Azzahra University, Vanak, Tehran, Iran. \\ mmh1331@yahoo.com
}

Received 15 July 2009; Accepted 7 September 2009

\begin{abstract}
Dioxo-octahydroxanthenes have been synthesized good yields via a reaction of aldehydes and dimedone in the presence of cellulose sulfonic acid as a heterogeneous catalyst under solvent-free condition.
\end{abstract}

Keywords: Xanthene derivatives, Solvent-free condition, Cellulose sulfonic acid, Heterogeneous catalyst.

\section{Introduction}

Xanthene derivatives are very important heterocyclic compounds and have been widely used as dyes fluorescent materials for visualization of bio-molecules and laser technologies due to their useful spectroscopic properties ${ }^{1}$. They have been reported for their agricultural bactericide activity ${ }^{2}$, photodynamic therapy ${ }^{3}$, antiflammatory effect ${ }^{4}$ and antiviral activity ${ }^{5}$. These compounds are also utilized as antagonists for paralyzing action of zoxazolamine ${ }^{6}$ and in photodynamic therapy (PDT) ${ }^{7}$. The other useful applications of these heterocycles are as dyes $^{8}$, flouerescent materials for visualization of biomolecules ${ }^{9}$ and in laser technologies ${ }^{10}$. Due to their wide range of applications, these compounds have received a great deal of attention in connection with their synthesis. A wide variety of methods for the preparation of the xanthenes have been classified according to starting compounds, $e$. $g$. syntheses by cyclization of polycyclic aryltiflate esters ${ }^{11}$, intramolecular trapping of benzynes by phenols ${ }^{12}$ and reaction of aryloxymagnesium halides with triethylorthoformate ${ }^{13}$. However, many of these methods are associated with several short comings such as long reaction times (16 $\mathrm{h}$ to 5 days), expensive reagents, harsh conditions, low product yields, use of toxic organic solvents and difficulty in recovery and reusability of the catalysts. Heterogeneous catalysts have gained interesting attraction in recent years due to economic and environmental 
considerations. These catalysts are generally inexpensive and easily available. They can conveniently be handled and removed from the reaction mixture, thus making the experimental procedure simple and eco-friendly. As part of our continued interest in the development of highly expedient methods for the synthesis of heterocyclic compounds of biological importance ${ }^{14}$, we would like to report a simple and efficient method to produce 1,8-Dioxo-octahydroxanthenes in very good yields catalyzed by cellulose sulfonic acid as a heterogeneous and reusable ecofriendly catalyst under solvent-free conditions (Scheme 1).

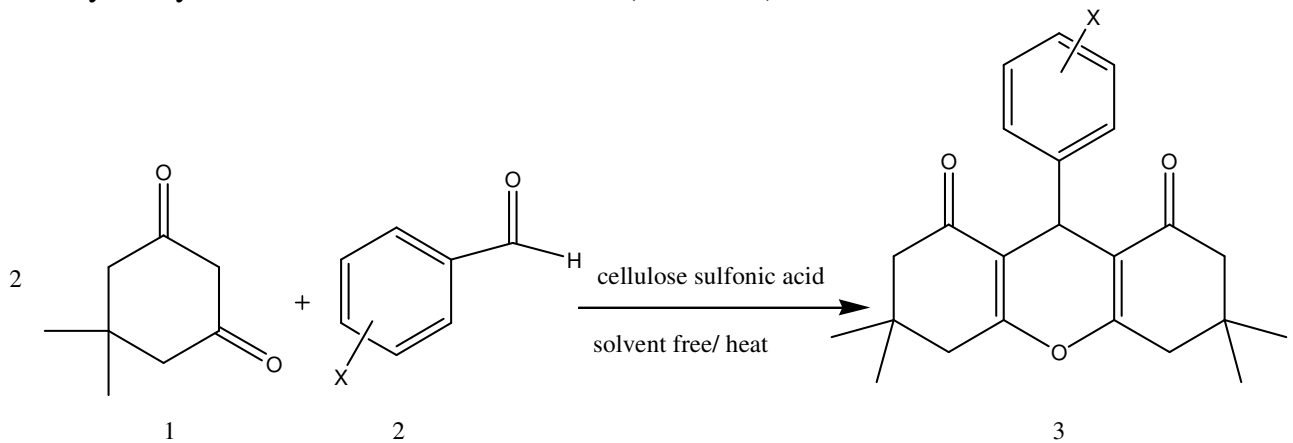

\section{Experimental}

\section{Scheme 1}

Chemicals were purchased from the Fluka, Merck and Aldrich chemical companies. Melting points were measured with a Bamstead Electrothermal 9200 apparatus and are uncorrected. GC/MS spectra were recorded on an Agilent Technologies 6890 network GC system and an Agilent 5973 network Mass selective detector. ${ }^{1} \mathrm{HNMR}$ spectra were recorded on a Bruker DRX Avance spectrometer at $300 \mathrm{MHZ}$, respectively, with $\mathrm{CDCl}_{3}$ as solvent. IR spectra were recorded from $\mathrm{KBr}$ disk on the FT-IR Bruker Tensor 27. Thin layer chromatography (TLC) on commercial aluminum-backed plates of silica gel, 60 F254 was used to monitor the progress of reactions.

\section{Preparation of 1, 8-dioxo-octahydroxanthenes General procedure}

A mixture of an aromatic aldehyde $(1 \mathrm{mmol})$, dimedone $(2 \mathrm{mmol})$ and cellulose sulfonic acid $(0.05 \mathrm{~g})$ was heated at $110{ }^{\circ} \mathrm{C}$. The progress of the reaction was monitored by TLC. After completion of the reaction, hot ethanol or methanol was added to the mixture and the catalyst was filtered off. The pure product was obtained by recrystallization from the solvent.

Synthesis of 3,4,6-tetrahydro-3,3,6,6-tetramethyl-9-phenyl-2H-xanthane-1,8 (5H,9H)dione (4a)

M.p: $206^{\circ} \mathrm{C}$. IR (KBr) $\left(v_{\max }, \mathrm{cm}^{-1}\right): 1670,1674(\mathrm{C}=\mathrm{O}) ;{ }^{1} \mathrm{H} \mathrm{NMR}\left(\mathrm{CDCl}_{3}, 300 \mathrm{MHz}\right) \delta_{\mathrm{H}}$ $(\mathrm{ppm}): 1.12(12 \mathrm{H}, \mathrm{s}), 2.01(4 \mathrm{H}, \mathrm{s}), 2.88(4 \mathrm{H}, \mathrm{s}), 3.46(1 \mathrm{H}, \mathrm{s}), 7.21-7.30(\mathrm{~m}, 5 \mathrm{H}$, aromatic $\mathrm{CH})$.

\section{Results and Discussion}

In a typical general experimental procedure, a mixture of dimedone and aldehyde was heated in the presence of a catalytic amount of cellulose sulfonic acid, the corresponding products were obtained in good yields. The results are summarized in Table 1. The catalyst plays a crucial role in the success of the reaction in terms of time and the yields. 
In the absence of the catalyst, the reaction of benzaldehyde with dimedone as an example, could be carried out but the product was obtained in very low yield after prolonged time. The catalyst is very active, stable to air and moisture, nontoxic and inexpensive. In addition, it can be quantitatively recovered by filtration and reused. We were able to separate cellulose sulfuric acid from the reaction medium easily by washing with $\mathrm{CH}_{2} \mathrm{Cl}_{2}$. After drying it was reused for subsequent reactions.

Table 1. Solvent-free synthesis of 1,8-dioxo-octahydroxanthene derivatives catalyzed by cellulose sulfonic acid.

\begin{tabular}{lcccccc}
\hline \multirow{2}{*}{ Entry } & \multirow{2}{*}{$\mathrm{X}$} & \multirow{2}{*}{ Product } & \multirow{2}{*}{ Time, h } & \multirow{2}{*}{ Yield, $\%^{\mathrm{a}}$} & \multicolumn{2}{c}{$\mathrm{m} . \mathrm{p},{ }^{\circ} \mathrm{C}$} \\
\hline 1 & $\mathrm{H}$ & $3 \mathrm{a}$ & 5 & 94 & 206 & $204-205^{15}$ \\
2 & $4-\mathrm{OH}$ & $3 \mathrm{~b}$ & 6 & 95 & 231 & $228-230^{16}$ \\
3 & $4-\mathrm{Br}$ & $3 \mathrm{c}$ & 5 & 94 & 225 & $222-224^{16}$ \\
4 & $3-\mathrm{NO}_{2}$ & $3 \mathrm{~d}$ & 5 & 95 & 167 & $168-170^{16}$ \\
5 & $4-\mathrm{NO}_{2}$ & $3 \mathrm{e}$ & 5 & 95 & 227 & $226-228^{16}$ \\
6 & $4-\mathrm{Cl}^{16}$ & $3 \mathrm{f}$ & 5 & 94 & 229 & $228-230^{16}$ \\
7 & $4-\mathrm{OCH}_{3}$ & $3 \mathrm{~g}$ & 6 & 95 & 243 & $241-243^{15}$ \\
8 & $4-\mathrm{CH}_{3}$ & $3 \mathrm{~h}$ & 6 & 94 & 219 & $217-218^{15}$ \\
\hline
\end{tabular}

Yields refer to isolated products.

Thus, this process could be also interesting for large-scale synthesis. In order to show the general applicability of the method, the reaction of structurally diverse aldehydes with dimedone (Scheme 1) under similar conditions was investigated. By this method, the reactions were carried out easily and very cleanly in the presence of cellulose sulfonic acid $(0.05 \mathrm{~g})$ at $110{ }^{\circ} \mathrm{C}$ under solvent-free conditions to produce xanthene derivatives in good yields and no undesirable by-products are observed. This protocol offers advantages in terms of its simple procedure and work-up and excellent yields. The experimental procedure is very simple, convenient and has the ability to tolerate a variety of other functional groups such as methyl, methoxy, nitro, hydroxyl, halide under the reaction conditions. It was indicated that both electron rich and electron deficient aldehydes worked well, mostly leading to high yields of products. It is noteworthy to mention that similar results were obtained in $\mathrm{H}_{2} \mathrm{O}$, but in longer reaction times. All reactions were carried out under solvent-free condition at $110{ }^{\circ} \mathrm{C}$ and the desired products were characterized by melting points, ${ }^{1} \mathrm{HNMR}$ and IR spectroscopic analyses. The optimum temperature was also examined using the reaction of benzaldehyde and dimedone in the presence of cellulose sulfonic acid under solvent-free condition and the best result was obtained at $110{ }^{\circ} \mathrm{C}$. Among the tested solvents such as methanol, ethanol, DMF, $\mathrm{CH}_{3} \mathrm{CN}$, chloroform, 1,2-dichloroethane and solvent-free system, the reaction was more facile and proceeded to gave highest yield, under solvent free conditions.

In summary, we have found a simple, convenient, straightforward and practical procedure for the synthesis of xanthene derivatives under solvent-free condition. All starting materials are readily available from commercial sources. Moreover, there is no need for dry solvents or protecting gas atmospheres. Some advantages of this procedure are: 1) the experimental simplicity and the easy work-up procedure, 2) the compatibility with various functional groups, 3) use of the inexpensive, green, easy to handle and reusable catalyst and 4) high yields of the products. The procedure is very simple and can be used as an alternative to the existing procedures. 


\section{Acknowledgments}

Prof. Hossein A. Oskooie gratefully acknowledges partial financial support from the research council of Azzahra University.

\section{References}

1. (a) Menchen S M, Benson S C, Lam J Y L, Zhen J Y L, Sun W, Rosenblum D, Khan B B and Taing S H, U S M, Patent 6, 2003, 583, 168; (b) Banerjee A and Mukherjee A K, Stain Technol., 1981, 56, 83; (c) Reynolds G A, Tuccio S A, Peterson O G and Specht D P, Germany Patent DE2109040, 1971.

2. Hideo T, Jpn Tokkyo Koho Chem Abstr., 1981, 95, 80922b JP56005480. 1981.

3. Ion R M, Albulescu C Sirkecioglu O and Talinli N, Intenet Photochem Photobiol., 2000.

4. Poupelin J P, Saint-Ruf G, Foussard-Blanpin O, Narcisse G, Uchida-Ernouf G and Lacroix R, Eur J Med Chem., 1978, 13, 67.

5. Lambert R W, Martin J A, Merrett J H, Parkes K E B and Thomas G J, PCT Int Appl WO9706178, 1997.

6. (a) Saint-Ruf G, De A and Hieu H T, Bull Chim Ther., 1972, 7, 83-86; (b) Saint- Ruf G and Hieu H T, Poupelin J P, Naturwissenschaften., 1975, 62, 584-585.

7. Ion R M, Frackowiak D, Planner A and Wiktorowicz K, Acta Biochim Pol., 1998, 45, 833-845.

8. (a) Banerjee A and Mukherjee A K, Stain Technol., 1981, 56, 83; (b) Menchen S M, Benson S C, Lam J Y L, Zhen W, Sun D, Rosenblum B B, Khan S H and Taing M U S, Patent, US 6583168, 2003.

9. Knight C G and Stephens T, Biochem J., 1989, 258, 683-689.

10. Sirkecioglu O, Talinli N and Akar A, J Chem Res (S)., 1995, 502.

11 Wang J Q and Harvey R G, Tetrahedron, 2002, 58, 5927.

12. (a) Knight D W, Little P B, J Chem Soc Perkin Trans.1, 2001, 14, 1771; (b) Knight D W and Little P B, Synlett., 1998, 1141.

13. (a) Casiraghi G, Casnati G and Cornia M, Tetrahedron Lett., 1973, 14, 679; (b) Casiraghi G, Casnati G, Catellani M and Corina M, Synthesis, 1974, 564.

14. (a) Bamoharram F F, Heravi M M, Roshani M, Gharib A and Jahangir M, Applied Cata., 2006, 302, 42; (b) Heravi M M, Hekmatshoar R and Pedram L, J Mol Cata A Chem., 2005, 89, 231; (c) Tajbakhsh M, Mohajerani B, Heravi M M and Ahmadi A N, J Mol Cata A Chem., 2005, 236, 216-219; (d) Heravi M M, Motamedi R, Siefi N and Bamoharram F F, J Mol Cata., 2006, 249, 1; (e) Bamoharram F F, Heravi M M and Roshani M, J Chin Chem Soc., 2007, 54, 1017; (f) Heravi M M, Bakhtiari K and Oskooie H A, J Chin Chem Soc., 2007, 54, 579; (g) Heravi M M Oskooie H and Baghernejad B, J Chin Chem Soc., 2007, 54, 767.

15. Horning E C and Horing M G, J Org Chem., 1964, 11, 95.

16. Jin T S, Zhang J S, Xio J C, Wang A.Q and Li T S, Synlett., 2004, 5, 866. 


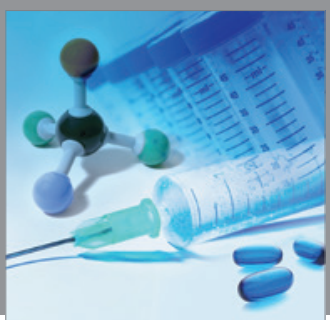

International Journal of

Medicinal Chemistry

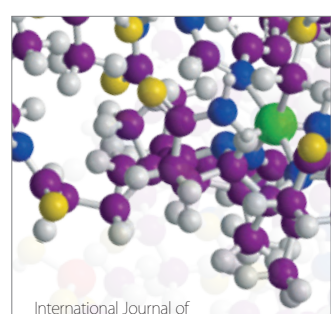

Carbohydrate Chemistry

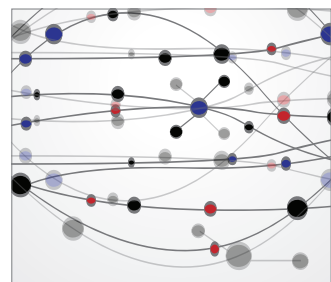

The Scientific World Journal
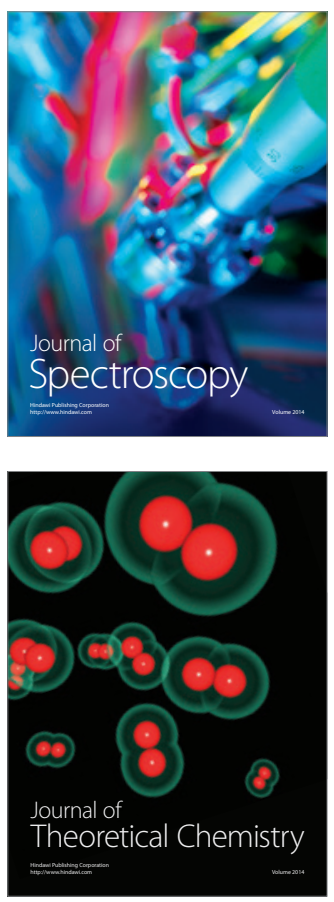
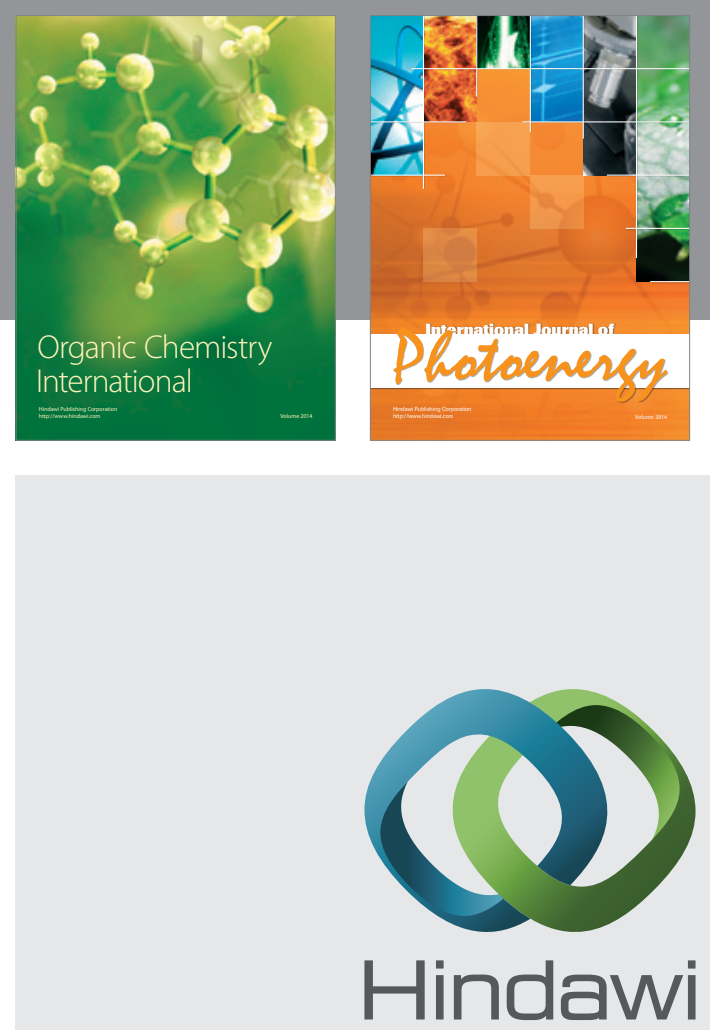

Submit your manuscripts at

http://www.hindawi.com
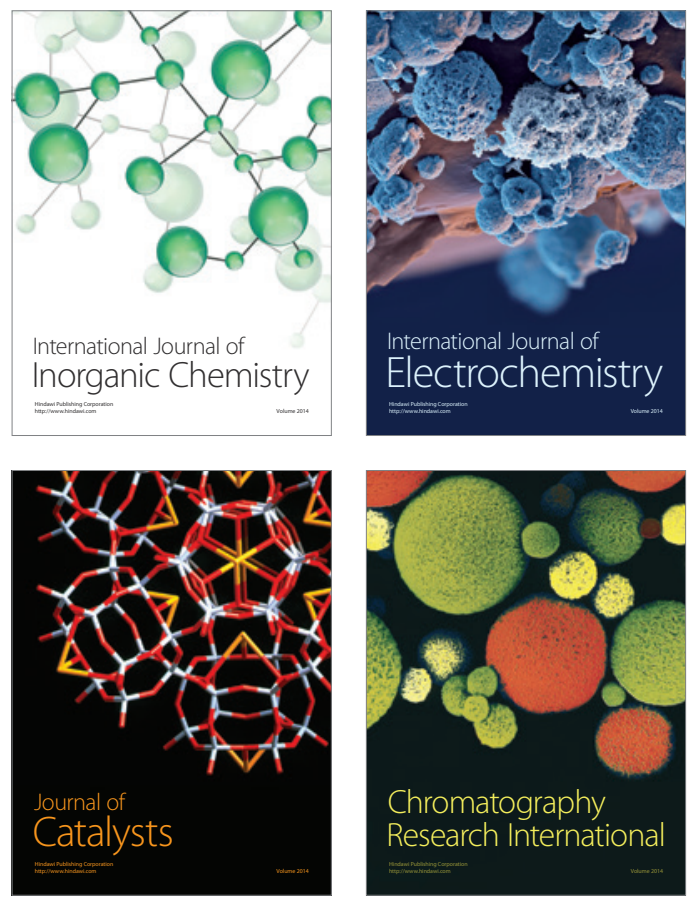
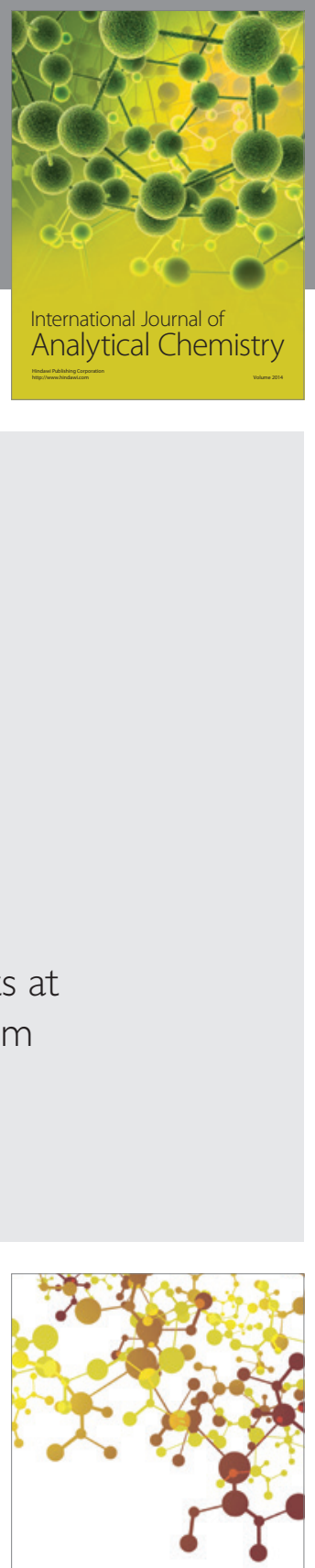

Journal of

Applied Chemistry
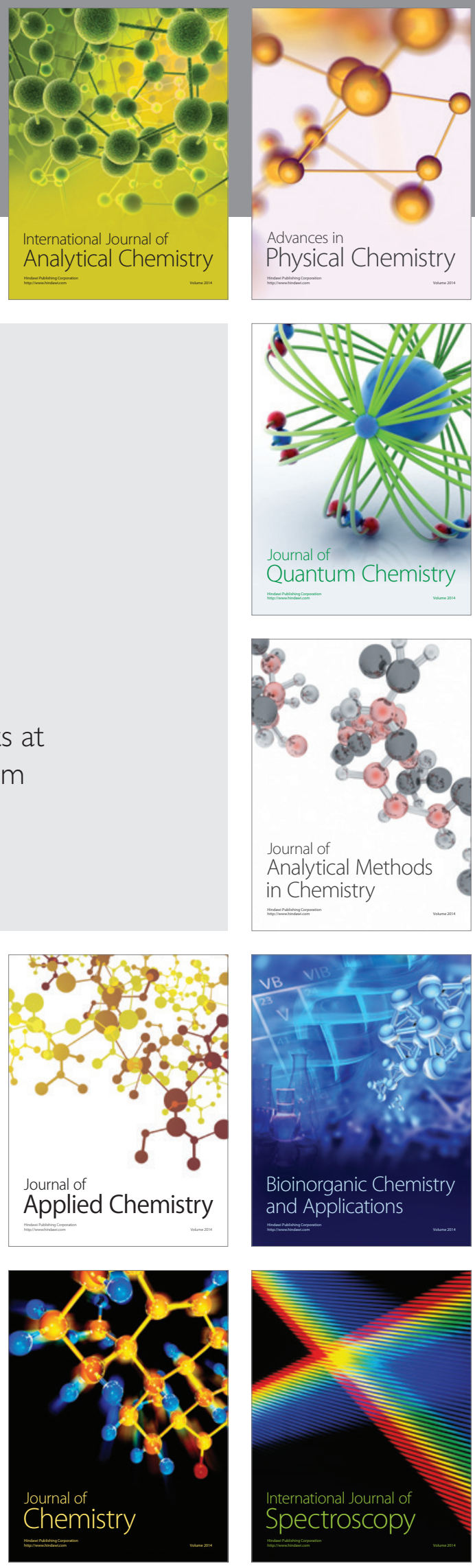